\title{
Analyzing Usage of Various Study Resources by Engineering Students
}

\section{Dr. Pradeep Kashinath Waychal, NMIMS University}

Dr Pradeep Waychal is a founder trustee and the chair of Guruji Education Foundation that provides holistic support to the education of underprivileged students and operates on funding from friends. The foundation has recently extended its work in diverse areas such research in engineering education, youth employability and teaching computer science to adolescents. Earlier, Dr Waychal has worked at Patni Computer Systems for 20 years in various positions including the head of innovations, NMIMS as the director Shirpur campus and at College of Engineering Pune (COEP) as the founder head of the innovation Center.

Dr Waychal earned his Ph D in the area of developing Innovation Competencies in Information System Organizations from IIT Bombay and M Tech in Control Engineering from IIT Delhi. He has presented keynote / invited talks in many high prole international conferences and has published papers in peerreviewed journals. He / his teams have won awards in Engineering Education, Innovation, Six Sigma, and Knowledge Management at international events. Recently, his paper won the Best Teaching Strategies Paper award at the most respected international conference in the area of engineering education - Annual conference of American Society of Engineering Education (ASEE). His current research interests are engineering education, software engineering, and developing innovative entrepreneurs and intrapreneurs. 


\section{Analyzing usage of various study resources by engineering students}

\section{Introduction}

We define self-study as study without direct supervision or attendance in a class. Students primarily undertake it for comprehensive examinations and use a variety of resources for that. This area does not seem to have attracted enough researchers. Grave has studied the amount of time students spend on the coursework versus self-study and found that on average students spend 19 hours on coursework and 12 hours on selfstudy per week. ${ }^{1}$ Dolton et al. studied the relationship between students' study time allocation and examination performance, and found that time spent on lectures is more productive than time spent on selfstudy. $^{2}$ Inglis et al. observed how often students attended live face-to-face lectures, accessed online recorded lectures, and visited a mathematics learning support center during a multivariate calculus course. ${ }^{3}$ Krause et al. have developed an instrument to understand use of resources for self-study. ${ }^{4}$ We have adapted that with some modifications for our experiment.

We found that undergraduate engineering students from an Indian college prefer going through their classroom notes, reading textbooks and discussing with classmates or friends during self-study for their comprehensive examinations. There are minor variations in this pattern between the freshman (first year) and other students. The major contribution of the paper is to analyze students' use of resources for their selfstudy for the comprehensive examinations so that teachers can plan their teaching and administrators and librarians can plan their resources. The next section outlines the research design that includes analysis and interpretation of the collected data and concluding remarks.

\section{Research Design}

Our study analyzed resources that undergraduate engineering students use while doing regular study for comprehensive examinations. We have outlined the overall research design in Figure 1.

\section{Objective, Scope and Type}

Students spend considerable time on self-study. Administrators and faculty must understand the resources used for that purpose. Earlier studies have included limited number of students i.e. around forty. ${ }^{4}$ Our study was larger in scale - we surveyed close to 200 students by randomly inviting $30 \%$ students from each year of study and each department from an undergraduate engineering program. We also studied differences in use of resources by freshmen and other students.

Our research is descriptive, diagnostic, cross-sectional, and field setting. Descriptive research describes the characteristics of a population being studied and does not explore the reasons for those characteristics. Diagnostic research studies determine the frequency with which something occurs or its association with something else. We did not study the resource usage over time but at a particular cross section, making the study cross-sectional. Our research covers real life situations and, therefore, is a field-setting study. 


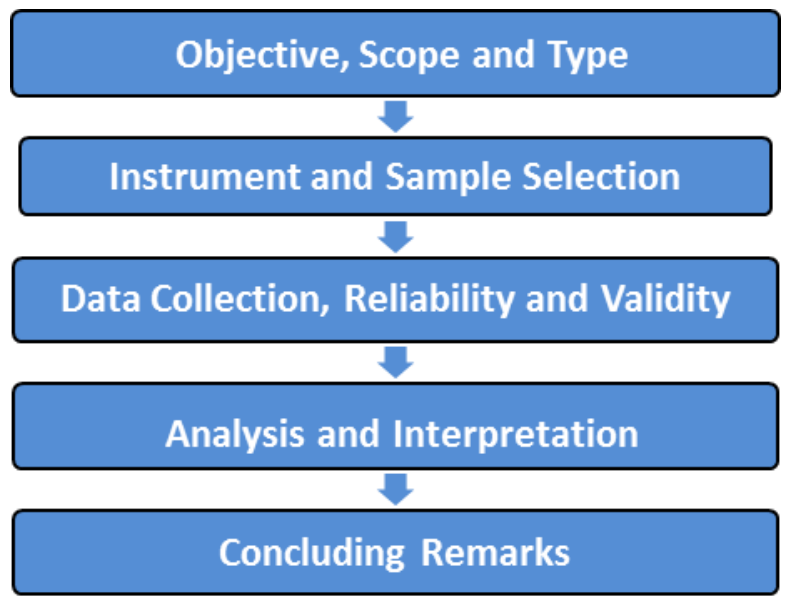

Figure 1 Research design

\section{Instruments and Sample Selection}

This is a critical step as it maps research problem to mathematical domain. We used the form designed by Krause et $\mathrm{al}^{4}$ and made some modifications such as not including web resources developed by faculty, and teaching assistants. These options were not available at the university, where we carried out the experiment. Our form is provided in Appendix A.

We carried out the experiment at an Indian university campus that has several engineering and other undergraduate programs. The university campus is located in a tier 3 city and hosts close to 900 of engineering students. The university has a well-equipped library that provides textbooks and reference books. The library has one textbook per five students and issues three books at a time for fifteen days. Our sample consisted of randomly chosen students from each year of study and each department of undergraduate engineering program. The departments covered are Computer Engineering, Information Technology, Electronics and Telecommunication Engineering, Mechanical Engineering, and Civil Engineering. We randomly chose around $30 \%$ of students from every program making the total sample size 246.

While most of the students were admitted to the four year Undergraduate (UG) engineering program after twelve years of schooling, a few of them had lateral entries in the second year of the program after ten years of schooling followed by three years of engineering diploma. The college is one of the best in the region and attracts above average students but they have noticeable variations in performance in the entrance examinations and in courses prior to the ongoing engineering program.

\section{Data Collection, Reliability and Validity, Analysis and Interpretation}

We randomly chose $30 \%$ of the students from each class making the total sample size 246 . We invited them to an auditorium for the survey. Of them, 195 students participated in the survey $(\mathrm{N}=195)$. We apprised them importance of the survey and administered it using hard copy forms. We have shown the details of the respondents in Table 1. 
Table 1: Number of total, selected, and responded students from each class.

\begin{tabular}{cccc}
\hline Class & $\begin{array}{c}\text { Total students in the } \\
\text { class }\end{array}$ & $\begin{array}{c}\text { Number of students } \\
\text { selected (around 30\%) }\end{array}$ & $\begin{array}{c}\text { Number of students } \\
\text { responded }\end{array}$ \\
\hline First Year (Freshman) & 214 & 64 & 60 \\
\hline Second Year (Sophomore) & 193 & 58 & 55 \\
\hline Third Year (Junior) & 227 & 69 & 42 \\
\hline Fourth Year (Senior) & 184 & 55 & 38 \\
\hline Total & $\mathbf{8 9 8}$ & $\mathbf{2 4 6}$ & $\mathbf{1 9 5}$ \\
\hline
\end{tabular}

We had varied responses from different classes. However, we had chosen samples randomly and the minimum response from a class was more than $18 \%$ of the class population, making aggregated analysis of the responses statistically valid.

Reliability and Validity

It is important to conduct a thorough measurement analysis of the instrument. It gives assurance that the findings reflect accurate measures and that results are trustworthy. Test reliability indicates the extent to which individual differences in scores are 'true' differences. As a proof of reliability, we chose two random sets of 25 sample records and confirmed that they are not statistically different, i.e. the means of the two sets are within a standard deviation as given in Table 2. We also carried out two-sample $\mathrm{T}$ test that resulted in p-value of 0.82 , indicating that the two samples do not have different means.

Table 2: Means and standard deviations of two random samples of 25 data-points.

\begin{tabular}{lcccc}
\hline Resource & Sample A - Mean & $\begin{array}{l}\text { Sample A }- \text { Std } \\
\text { Dev }\end{array}$ & Sample B - Mean & $\begin{array}{l}\text { Sample B - Std } \\
\text { Dev }\end{array}$ \\
\hline $\begin{array}{l}\text { Your own } \\
\text { classroom notes }\end{array}$ & 3.1 & 1.1 & 3.2 & 0.8 \\
\hline $\begin{array}{l}\text { Homework } \\
\text { problems }\end{array}$ & 2.3 & 1.2 & 2.4 & 1.2 \\
\hline $\begin{array}{l}\text { Posted lecture } \\
\text { slides }\end{array}$ & 2.6 & 1.1 & 2.2 & 1.2 \\
\hline $\begin{array}{l}\text { Old exams or } \\
\text { quizzes }\end{array}$ & 2.0 & 1.4 & 1.9 & 1.4 \\
\hline \begin{tabular}{l} 
Textbook readings \\
\hline $\begin{array}{l}\text { Classmates / } \\
\text { friends }\end{array}$
\end{tabular} & 2.6 & 1.3 & 3.2 & 0.9 \\
\hline $\begin{array}{l}\text { Instructor } \\
\text { Tutoring service }\end{array}$ & 2.8 & 1.0 & 2.7 & 0.9 \\
\hline Google & 1.5 & 1.2 & 2.2 & 1.3 \\
\hline
\end{tabular}


Analysis

We have tabulated responses and analysis making using Tukey method using Minitab version 17 of all the students to 'How often did you use the following resources to help you study for your exam?' on the scale of 0 to 4 ( 0 meaning never and 4 meaning always) in Table 3.

Table 3: Reponses of All Engineering Students to Exam Resources Used

(0 meaning never and 4 meaning always; Grouping Information using Tukey Method with 95\% confidence)

\begin{tabular}{ccc}
\hline Resource & Mean & ${ }^{*}$ Grouping \\
\hline Your Own Classroom Notes & 2.76 & $\mathrm{~A}$ \\
\hline Textbook Readings & 2.64 & $\mathrm{~A}$ \\
\hline Classmates/Friends & 2.51 & $\mathrm{AB}$ \\
\hline Posted Lecture Slides & 2.10 & $\mathrm{BC}$ \\
\hline Homework Problems & 2.04 & $\mathrm{C}$ \\
\hline Google & 1.94 & $\mathrm{C}$ \\
\hline Instructor & 1.83 & $\mathrm{C}$ \\
\hline Old Exams Or Quizzes & 1.69 & $\mathrm{C}$ \\
\hline Tutoring Service & 1.16 & $\mathrm{D}$ \\
\hline
\end{tabular}

*Means that do not share a letter are significantly different.

Students' top preferences seem to be their classroom notes and textbooks. Consulting classmates or friends is not significantly different from those two as well as using posted lecture slides. Homework problems,

Google, asking instructors and old exams or quizzes are at the same level and not significantly different from posted lecture slides. Tutoring service is the least preferred option. That could be due to the remoteness of the campus resulting in poor availability of the tutors.

We have segmented freshmen and others and analyzed their resource usage. We have tabulated responses and analysis using Tukey method using Minitab version 17 of the freshman (first year) students to 'How often did you use the following resources to help you study for your exam?' on the scale of 0 to 4 (0 meaning never and 4 meaning always) in Table 4.

Table 4: Reponses of Freshman Engineering Students to Exam Resources Used

(0 meaning never and 4 meaning always; Grouping Information using Tukey Method with 95\% confidence)

\begin{tabular}{ccc}
\hline Resource & Mean & *Grouping \\
\hline Your Own Classroom Notes & 2.90 & $\mathrm{~A}$ \\
\hline Textbook Readings & 2.77 & $\mathrm{AB}$ \\
\hline Classmates/Friends & 2.57 & $\mathrm{ABC}$ \\
\hline Homework Problems & 2.07 & $\mathrm{BCD}$ \\
\hline Google & 1.88 & $\mathrm{CDE}$ \\
\hline Instructor & 1.83 & $\mathrm{DE}$ \\
\hline Posted Lecture Slides & 1.53 & $\mathrm{DEF}$ \\
\hline Old Exams Or Quizzes & 1.25 & $\mathrm{EF}$ \\
\hline Tutoring Service & 0.93 & $\mathrm{~F}$
\end{tabular}

*Means that do not share a letter are significantly different. 
The top preferences of the first year (freshman) students do not seem to differ much as compared to 'all the students'. The freshmen tend to rely on their own classroom notes, reading textbooks, and consulting classmates or friends, the most. The last two are not significantly different from the homework problems. Discussing with classmates / friends' options is not significantly different from homework problems and accessing Google. Further, homework problems are not significantly different from accessing Google, asking instructor and using posted lecture slides. Accessing Google is not significantly different from discussing with instructors, using posted lecture slides, and using old exams or quizzes. Posted lecture slides and old exams or quizzes are not different from using tutoring service.

While responses of all the students did not show much difference in the preferences, responses of the first year (freshman) students showed much difference. Therefore, we decided to analyze responses of other (sophomore, junior and senior) students, separately. We have tabulated responses and analysis using Tukey method using Minitab version 17 of all 'other' students to 'How often did you use the following resources to help you study for your exam?' on the scale of 0 to 4 ( 0 meaning never and 4 meaning always) in Table 5.

Table 5: Reponses of Sophomore, Junior, and Senior Engineering Students to Exam Resources Used

( 0 meaning never and 4 meaning always; Grouping Information using Tukey Method with 95\% confidence)

\begin{tabular}{ccc}
\hline Resource & Mean & ${ }^{*}$ Grouping \\
\hline Your Own Classroom Notes & 2.71 & $\mathrm{~A}$ \\
\hline Textbook Readings & 2.58 & $\mathrm{~A}$ \\
\hline Classmates/Friends & 2.48 & $\mathrm{AB}$ \\
\hline Posted Lecture Slides & 2.36 & $\mathrm{ABC}$ \\
\hline Homework Problems & 2.03 & $\mathrm{BCD}$ \\
\hline Google & 1.97 & $\mathrm{BCD}$ \\
\hline Old Exams Or Quizzes & 1.89 & $\mathrm{CD}$ \\
\hline Instructor & 1.83 & $\mathrm{D}$ \\
\hline Tutoring Service & 1.27 & $\mathrm{E}$ \\
\hline
\end{tabular}

*Means that do not share a letter are significantly different.

The top preferences of this group do not seem to differ much. They tend to use their own classroom notes, read textbooks, consult classmates or friends, and use posted lecture slides. Discussing with classmates and friends is not significantly different from using posted lecture slides, homework problems, and accessing Google. Further, posted lecture slides are not significantly different using homework problems, accessing Google, and using old exams or quizzes. Moreover, homework problems are not significantly different from accessing Google, using old exams or quizzes, and asking instructor. Relying on tutoring service is the least preferred resource.

Interpretation

It is clear that all students enormously rely on their classroom notes. The teachers need to take efforts so that they can provide proper notes. Textbook readings and discussions with classmates and friends are also favored resources. It is important to provide sufficient number of textbooks in libraries. Since students find it helpful to consult their colleagues, libraries can provide some soundproof discussion rooms. Also during the examination preparation time, we can organize sessions where students with good academics can help others. We can impress upon the good students benefits of such sessions by making them understand that teaching is the best way of learning. Posted lecture slides tend to be cryptic and, therefore, may not be favored. Most of 
the question papers shy away from problem solving and rely on descriptive answers, which may be a deterrent from studying through homework problems. Students may be using old exams or quizzes as a supplementary and not main resource. That may be the reason for it being a less preferred resource. Tutoring service is the least preferred option and that could be due to the remoteness of the campus resulting in poor availability of the tutors. It is important that faculty understands current usage of the resources, the reasons behind them, correct the reasons, and steer the resource usage in the right direction.

\section{Concluding Remarks}

Engineering education - all over the world - is undergoing transformation. The rise of the Internet and allied technologies, and regulatory requirement of outcome-based education that is rooted in the challenging $21^{\text {st }}$ century problems are the driving forces behind this transformation. These changes are making newer resources available as well as imperative for self-study. It is important to analyze the use of these resources so that faculty members can plan for various resources appropriately, and steer usage of the resources in the right direction, and administrators and librarians can plan for the required resources.

We found that studying from classroom notes, discussing with classmates / friends, and reading from textbooks are the most preferred resources when students study for comprehensive examinations. We did not observe any significant difference between the first year (freshman) and other students. Further segmentation into the years of study and the departments may provide more insights. Some of the resource usage may be due to the current pattern of conducting examinations i.e. asking more closed and descriptive questions. Mere reading of classroom notes and textbooks may suffice for those types of questions. They may not accrue higher level of learning. We may have to change examination and pedagogical methods that could result in higher level of learning and changes in resource usage in the right direction. Krause et al. utilized formative feedbacks to develop new web-enabled resources and found students preferring them to textbooks, and registering better achievement. ${ }^{4}$

We plan to segment the students based on the year of study and the program to glean some more insights. We must repeat the experiment in different settings such as autonomous colleges, affiliated colleges, and different geographies to enhance our understanding of use of the resources. Analyzing use of resources in the context of courses, faculty, and their teaching methods can also be helpful. We can also study correlation, if any, between resources in use and performance at the examination.

In general, students and even many faculty members are not sufficiently information literate - they do not know sources of information and optimum ways to access them. It has to change. In case of students, we have to integrate information literacy instruction across their engineering curriculum. ${ }^{5,6 \text { and } 7}$ This can include regular interactive sessions on usage of available resources. ${ }^{8}$ In case of faculty, we have to organize specific seminars or sessions. These steps can influence use of the resources positively and significantly.

\section{Acknowledgements}

We thank Mr. Craig Beard, Engineering Library Division (ELD) Program Planning Chair, Mr. Jay Bhatt, the Chair of the Mentoring Committee, and anonymous reviewers for their insightful comments and multiple review iterations. We also thank all the students who participated in the survey and Mr. Abhay Joshi for reviewing early versions of the paper. 


\section{References}

1 Barbara S Grave, 'The Effect of Student Time Allocation on Academic Achievement', Education Economics, 19 (2011), 291-310.

2 Peter Dolton, Oscar D Marcenaro, and Lucia Navarro, 'The Effective Use of Student Time: A Stochastic Frontier Production Function Case Study', Economics of Education Review, 22 (2003), 547-60.

3 Matthew Inglis, Aruna Palipana, Sven Trenholm, and Joe Ward, 'Individual Differences in Students' Use of Optional Learning Resources', Journal of Computer Assisted Learning, 27 (2011), 490-502.

4 Stephen Krause, R. Baker Dale, R. Carberry Adam, L. Alford Terry, Ankeny Casey Jane, Brooks Bill Jay, Koretsky Milo, Waters Cindy, and J. Gibbons Brady, 'The Impact of Two-Way Formative Feedback and Web-Enabled Resources on Student Resource Use and Performance in Materials Courses', in ASEE Annual Conference Seattle (Seattle, Washington: ASEE Conferences, 2015).

5 MacAlpine Barbara, and Uddin Mahbub, 'Integrating Information Literacy across the Engineering Design Curriculum', (Austin, Texas: ASEE Conferences).

6 Barbara MacAlpine, 'Engineering+ Information Literacy= One Grand Design', age, 10 (2005), 1.

7 Information Literacy Committee, 'Expanding Horizons: Using Information in the 21st Century', (2008).

8 Julie Arnold, Robert Kackley, and Arnold Fortune, 'Hands-on Learning for Freshman Engineering Students', (2003). 


\section{APPENDix A:}

\section{STUdent Resource VALUE SuRVEY (SRVS)}

DIRECTIONS: Please read the questions below. Mark the box that corresponds to your level of agreement.

1. How often did you use the following resources to help you study for your exam?

$\begin{array}{cccc}\text { Never } & \text { Rarely } & \text { Sometimes } & \text { Frequently } \\ * 0 & * 1 & * 2 & * 3\end{array}$

Not Always Applicable $* 4$ (did not include)

a) your own classroom notes

b) homework problems

c) posted lecture slides

d) old exams or quizzes

e) textbook readings

f) classmates/friends

g) instructor

h) tutoring service

i) Google

- The numbers indicate weightage to the occurrences. 